appeared, however, to be generally more attractive in areas of the world where good coking coals were in short supply.

The annual report makes reference to other topics that must be of particular interest to the expert. In addition to the aforementioned special report, there is given a notable list of interesting publications released during the year on a wide variety of subjects, including the following : Future Trends in the Development of the Coking Industry by the director, Mr. G. W. Lee (Hodsman Memorial Lecture); a report on The Russian Coking Industry, 1962 ; and the scientific papers emanating from the fundamental studies at the Universities of Newcastle and Hull, carried out respectively under the guidance of Prof. W. F. K. Wynne Jones and Dr. J. J. Kipling.

A final word of comment relates to the benefits emerging from the many years of fruitful effort made by the Association on the scientific control of coke manufacture. This has involved the painstaking development of better methods of analysis and testing, and these have now been demonstrated to the industry with the help of a mobile laboratory and the necessary liaison staff. During recent years both the average level and the consistency of coke quality have improved throughout the industry. This is in no small measure due to the adoption of standard methods of sampling and assessment of the quality of coke, and these methods have also made possible the operation of a price structure based on coke quality.

The mobile laboratory has also served as a base for Association teams carrying out investigations at members' plants. This new service to members has strengthened the link between the staff of the Association and that of the industry served. This is an important feature of the Association's activities and has also been shown to be extremely valuable in other research associations supported by the Department of Scientific and Industrial Research. It goes without saying that success of the sort achieved by Mr. Lee and his staff also implies receptivity on the part of the industrial personnel.

R. J. SARJANT

\title{
RADIATION INJURY
}

$\mathrm{U}$ NDER the title Physical Factors and Modification of Radiation Injury the New York Academy of Sciences has published a number of papers and discussions given in Now York at the end of $1962 \%$. As such the publication is probably one of the most stimulating and rewarding volumes on radiobiology so far available.

The papers in the first section on "Physical Factors Modifying Response to Radiation" are each a delightful balance between a simple review of the subject and presentation of new experimental data with ideas for fundamental analysis and further thought. The subjects of radiation quality and biological effect; the effect of linear energy transfer (LET) as tested in biological systems from bacteria to mammalian cells in vitro and in vivo, and in whole animals; the relationship of LET to modification of radiation damage by dose fractionation, anoxia and chemical protectors, show how nearly funda. mental radiobiological research comes to solving some major problems of radiotherapy. In one group of papers,

* Annals of the New York Academy of Sciences. Vol. 114, Article 1: Physical Factors and Modification of Radiation Injury. Pp. 1-716. By York Academy of Sciences, 1964.) 12 dollars. however, related to the "Diagnosis, Treatment and Prognosis of Human Radiation Injury from Whole-body Exposure", one is struck by the difficulty of applying radiobiological data directly, and the empirical medical approach of considering each case at the bedside must still bo the prescribed course.

Somewhat in contrast to the foregoing, the papers in Part 2, resulting from the conference on "Modification of Radiation Injury by Bone Marrow Transplantation and Chemical Protection", are a mixture of detailed experimental work designed to shed light on one small part of the field, of interest only to the real expert; three or four excellent technical papers grouped together at the end of the volume; and unfortunately, at least one example of an æsthetically unpleasant experimental paper with remote scientific justification on the "Enhanced Survival of Skin Homografts in Mice with a Bacterial Infection".

The volume, with good bibliography, will be essential reading for those concerned with recent developments in radiobiology, and its applications to radiotherapy. It retains some of the overwhelming nature of the meeting itself, but has crystallized the main points of the conferences for easy assimilation. PATRICIA J. LINDOP

\section{ELIMINATING DETERGENT FOAM}

$\mathrm{T}$ HE elimination of detergent foam has been a problem of world-wide concern ever since the introduction of synthetic detergents on a large scale after the Second World War. It is still with us, but there are encouraging signs of a solution. The subject is discussed in a short but informative article in Rohm and Haas Reporter (Philadelphia, Pa., 22, No. 1, January-February 1964).

Surfactants are commonly classified as either 'soft' or 'hard'; the former are 'biodegradable', readily decomposing in the presence of bacteria in sewage plants, septic tanks and natural waters; the latter are non-biodegradable, resistant to bacterial decomposition. Most synthetic detergents to-day utilize hard surfactants; thus they do not degrade fast enough after fulfilling their cleansing function and their presence is constantly being revealed in rivers, sewage effluents, and so on. It is perhaps commonly assumed that the amount of foam provided by a detergent, for example, in shampoos, washing and dishwashing compounds, is a criterion of the efficiency of its cleaning action; actually the amount of foam has little to do with its cleansing power; it may look good to the housewife but its main function is that of floating out dirt particles, holding them in suspension until they are rinsed away. But it is what happens afterwards to this foam that is the concern of river boards, sewage disposal authorities and public health officials.

The Rohm and Haas Co. claims to be the first firm to offer a non-ionic surfactant for biodegradability by its introduction of 'Surfactant $D N-65$ ' in the summer of 1963. According to the article: "Now commercially available, the 100 per cent active, nonionic surfactant is supplied as a water-soluble liquid for detergent formulations. Surfactant $D N-65$ is rapidly degradable by the bacteria normally present in waste disposal systems and natural water supplies. The new detergent concentrate is designed to replace the conventional water-soluble octyl and nonyl phenoxy poly-ethoxy ethanol-type surfactants, where biodegradability is required. River 